\title{
Five steps for astronomers to communicate climate change effectively
}

\author{
Astronomers are trusted voices in the communication of science; our community should resist inundating people \\ with facts and figures but use its advantage to encourage the public to listen to climate change experts and \\ encourage the need for urgent cross-sectoral systemic change.
}

\section{Alison Anderson and Gina Maffey}

$\mathrm{C}$ limate change is one of the most serious challenges facing our planet and we are increasingly experiencing its dire effects with soaring temperatures, wildfires, floods and droughts. Within astronomy there is growing recognition of the urgency of the situation, the profession's impact on it and the need to communicate outside the academy ${ }^{1-3}$. Scientists are highly trusted by the public and tend to be seen as independent and non-controversial ${ }^{4}$. Astronomers are particularly well placed to communicate on climate change, given that the exciting nature of their subject often provides them with a platform in the media and the ability to reach out to very large numbers of people through a variety of public outreach events around the globe. Astronomy offers many entry points to talking about climate change, from the climate history of the terrestrial planets to the notion that there is no alternative planet for humans to live on: there is no 'Planet $\mathrm{B}^{\prime 3}$. We argue that there is a real window of opportunity for astronomers to engage with the topic and weave climate change into their public engagement activities. There is a large body of research in science and environmental communication that can inform practice in the astronomy community and here we summarize the key findings.

\section{Tell a story}

Effective climate change communication requires two-way dialogue and strong narratives. Telling stories enables audiences to make sense of complex issues and human-interest narratives tend to be more memorable than numbers or graphs 5 . Best-practice guides on climate change communication recommend emphasizing scientific consensus while carefully explaining how a degree of uncertainty is present in all scientific work ${ }^{6}$. Metaphors can influence people's attitudes to climate change, while strong visual images and analogies should be relatable and, where possible, include people ${ }^{7}$. When crafting

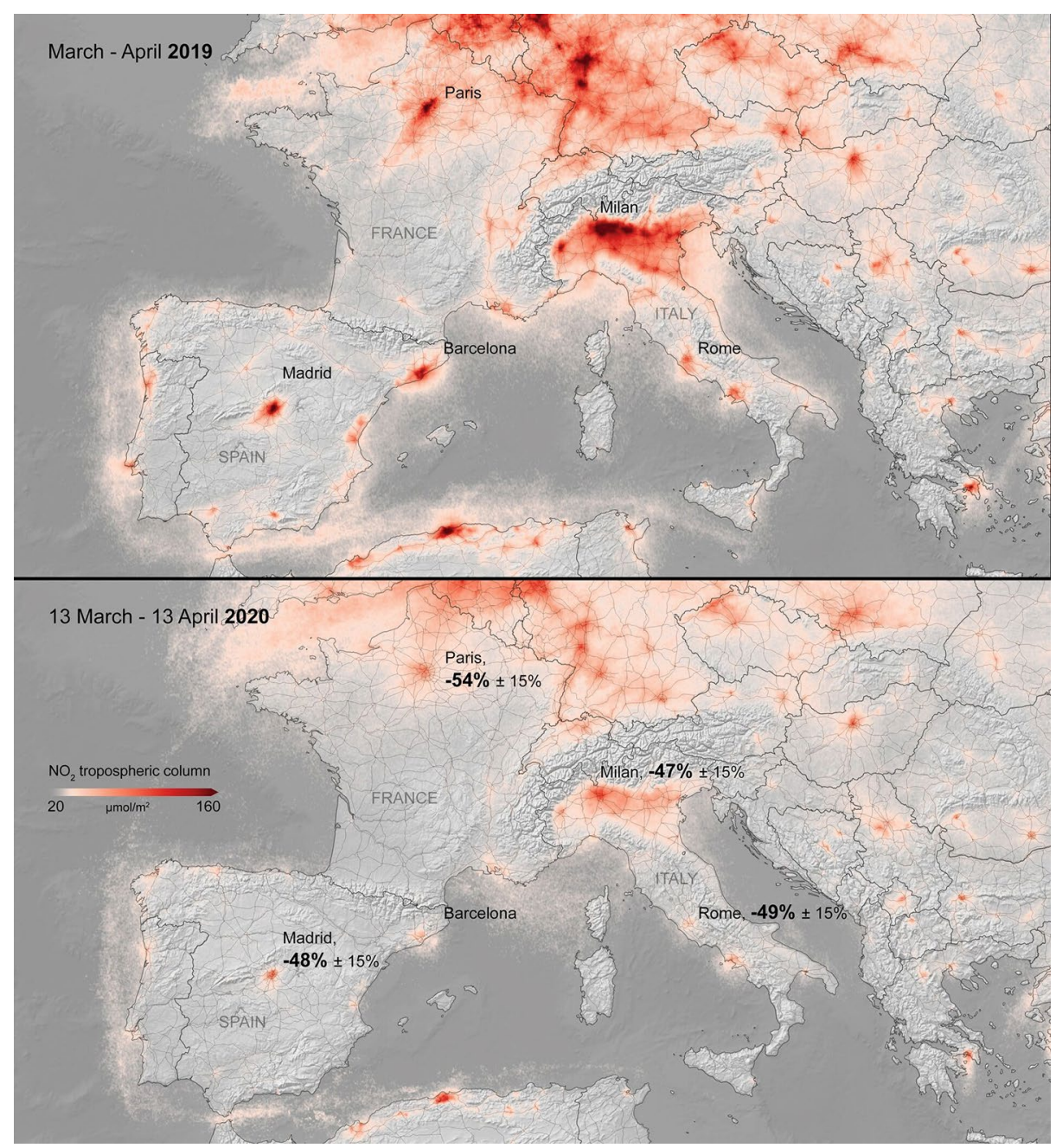

Fig. 1 | Nitrogen dioxide concentrations over Europe. These images use data from the Copernicus Sentinel-5P satellite to compare polluting nitrogen dioxide concentrations in March-April 2019 with the same period a year later, when pandemic restrictions were keeping many Europeans at home. Credit: Contains modified Copernicus Sentinel data (2019-20), processed by KNMI/ESA.

stories, however, it should be considered that the language and terminology used by scientists may not be shared by the public and can add to confusion about the issues $^{5,8}$. As Somerville and Hassol point out: "Scientists typically fail to craft simple clear messages and repeat them often. They commonly overdo the level of detail, and people can have difficulty in sorting out what is important... Many words that 

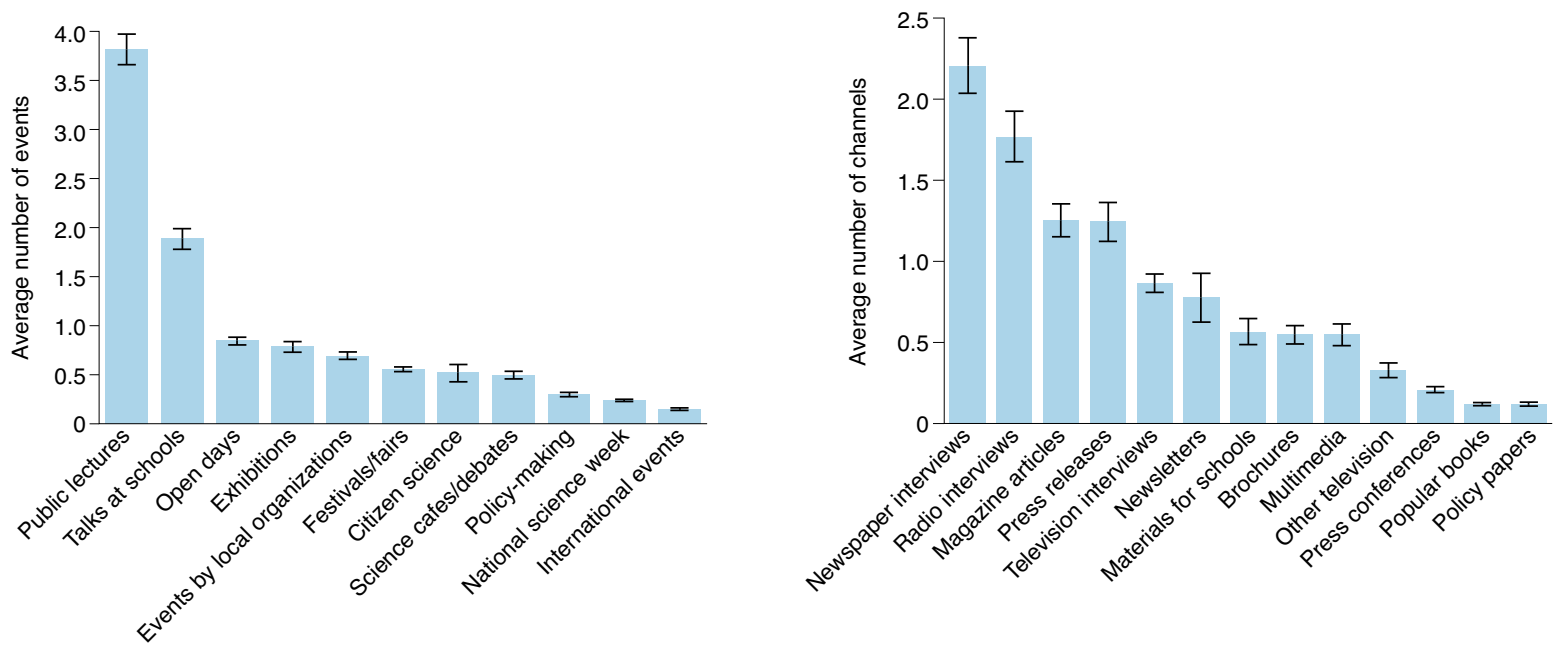

Fig. 2 | Astronomers typically engage in a high number of public engagement activities. This access to the public makes astronomers well placed to communicate on climate change. Credit: Figure reproduced with permission from ref. ${ }^{19}$, Springer Nature Ltd.

seem perfectly normal to scientists are incomprehensible jargon to the wider world. And there are usually simpler substitutes" 5 . A good example of this is the use of the word 'theory', which can be interpreted by the public as a mere hunch or speculation. A better choice of terminology would be 'scientific understanding' ${ }^{5}$. While language needs to be handled carefully in any climate communication, astronomers hold an advantage in that many projects naturally instil a sense of awe. Topics such as exoplanet exploration, habitability and atmospheric composition can act as bridges to reflect on human planetary needs. The fact that space agencies operate Earth-observing satellites as well as outward-looking astronomical observatories and space missions provides a connection between our planet and the rest of the Universe. For instance, observations from the European Space Agency's Copernicus Sentinel-5P satellite recently provided striking images charting the dramatic reduction in nitrogen dioxide concentrations as COVID-19 restrictions were applied across Europe (Fig. 1).

\section{Make it relevant}

Connecting to what matters to the audience is key, as is dynamic co-production of knowledge through dialogue. Despite increasingly experiencing the impact of climate change, it is still often perceived to be a psychologically distant and abstract issue. Citizens can be readily engaged with climate change through local environmental issues or meteorological conditions (for example, air quality, flooding), and linking to immediate and personally relevant issues $^{1,9}$. Participants in a study examining citizens' accounts of climate change in Brazil, South Africa and China found that they overwhelmingly framed their accounts in the context of locally salient issues ${ }^{10}$. Effective communication of climate change adaptation needs to highlight that climate change is currently visible at local levels. It should allow individuals to connect emotionally to the impacts experienced, particularly in situations in which they are psychologically distant ${ }^{11}$. Photography and film can be important tools here. In astronomy, many observatories operate in remote and fragile natural environments where resource use can be an evocative issue. Addressing environmental sustainability through community engagement can be an important step in ensuring that astronomical pursuits also recognize local impacts.

\section{Tailor the message}

Providing people with more knowledge will not fix the problem. Communicators have often assumed that the problem - in this instance, climate change - is largely one of a deficit in knowledge and understanding, and that communicating the science will encourage attitudinal and behaviour change. Recent research involving interviews with astronomers suggests that the community tends to view the public as homogenous with multiple deficits in knowledge ${ }^{12}$. There is a danger here that the information deficit model is applied, based on the assumption that providing people with greater information and explanation will move them to act. However, a long history of interdisciplinary science communication research demonstrates that messages need to be tailored to the specific audience ${ }^{13,14}$, with recognition of communication as a two-way process. The same message is likely to be received differently by different audiences, and effective climate change communication needs to be targeted while resonating with audience values and everyday lives ${ }^{15}$. Attitudes to climate change are shaped by socio-political values, and people tend to use their political and cultural orientations to filter information on the issues ${ }^{5,16}$. Although people hold a variety of sometimes conflicting values, research shows that those who identify with self-transcendent values (such as benevolence and loyalty), and who exhibit high levels of altruism, are more likely to engage in sustainable behaviour. By contrast, those who identify with self-enhancement values (such as personal ambition and materialism) are more likely to be sceptical about climate change and less likely to exhibit high levels of concern ${ }^{16}$. A substantial body of research demonstrates that those holding right-of-centre political views tend to be less concerned, more sceptical and less receptive to climate change messaging. Focus group research undertaken in the United Kingdom suggests that in order to engage such audiences it is best to frame energy efficiency in terms of avoiding waste, rather than the more contentious concept of preventing fuel poverty. Moreover, framing climate change in this way also has broad appeal for those from opposing political perspectives, whereas using a justice frame that works well with left-of-centre audiences tends to 
alienate right-of-centre individuals ${ }^{16}$. In addition to tailoring communication to specific demographic groups and according to political ideology and cultural orientation, it needs to be relatable and accessible with a clear storyline. As non-climate experts, astronomers can play a key role as scientifically aware and trusted voices. It is not necessarily about explaining all the details of climate change, but showing that, as scientists, astronomers trust and accept the expertise of climate scientists.

\section{Focus on solutions}

It is imperative that climate change communication is solution-focused. Efficacy is crucial - the belief that it is possible to do something, and if you do something it will make a difference. Research shows that doom-and-gloom messaging is often counter-productive and tends to leave people feeling apathetic, despondent and disempowered ${ }^{14,17}$. Fearful messages can mobilize people but they need to be combined with clear solutions that can be adopted ${ }^{17}$. This is particularly pertinent when considering that individuals have been shown to have a 'finite pool of worry' and too much focus on negative impacts can turn them off. As Moser and Dilling observe: “...risk information and fear-evoking images should be limited and always be combined with messages and information that provide specific, pragmatic help in realizing doable solutions... Importantly, communicators must establish a sense of collective response, especially by people in like social and cultural groups"18. Astronomy projects often have unique qualities in this respect, with many operating on an international level, holding strong public appeal and transcending cultural divides. While individual behaviour change is important, systemic change can occur only with collective action and pressure on industry and government to facilitate and incentivize large-scale societal shifts. Here again, astronomers can play an important role in communicating the need for urgent cross-sectoral systemic change.

\section{Embed change in astronomy}

It is not just a case of making the issues more visible; climate change communication needs to be accompanied by action at the individual and community level. Astronomers need to take a stance and engage as advocates beyond the academy. Astronomers typically take part in a high number of public engagement activities, especially when compared with scientists in other fields; a survey undertaken in 2016 found it to average approximately 18 activities per year for each communicative astronomer ${ }^{19}$. The majority of such events were public lectures and open days or talks in schools (Fig. 2). This provides an excellent opportunity to engage with different audiences on climate change through the topic of astronomy. Astronomers for Planet Earth is a rapidly growing movement that establishes a strong connection between astronomy and climate change, shares communication resources and tools, and amplifies the individual voices of those seeking climate justice ${ }^{20}$.

It should be noted that a global survey of astronomers showed that, regardless of the area of the world in which they worked, the most active science communicators were those who were more supported by their institutions in terms of resources ${ }^{19}$. Organizational resources and a supportive culture are key to encouraging more astronomers to engage in climate change communication and challenge misinformation and denial. Such outreach needs to be valued, incentivized and rewarded by institutions. There needs to be more training, funding and support from communications staff, and stricter funding requirements need to be introduced to prioritize sustainability engagement work. In particular, there is potential for more two-way dialogical and participatory forms of communication ${ }^{12}$. Climate change is (rightly) becoming an urgent issue in society today. Astronomers are able to use astronomy as a bridge to introduce topics that hold increasing relevance and impact for individuals' everyday lives.
We are at a crucial point in history where the astronomy community can make a hugely important contribution to engaging the public with one of the most serious challenges of our time.

Alison Anderson (D) 1,2四 and Gina Maffey (D) ${ }^{3}$ ${ }^{1}$ University of Plymouth, Plymouth, UK. ${ }^{2}$ Monash University, Melbourne, Victoria, Australia. ${ }^{3}$ Stichting Wildeor, Dwingeloo, The Netherlands.

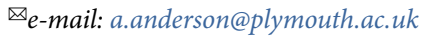

Published online: 15 September 2021 https://doi.org/10.1038/s41550-021-01481-2

References

1. Williamson, K., Rector, T. A. \& Lowenthal, J. Bull. Am. Astron. Soc. https://baas.aas.org/pub/2020n7i049 (2019).

2. Burtscher, L. et al. Nat. Astron. 4, 823-825 (2020).

3. Cantalloube, F. et al. Nat. Astron. 4, 826-829 (2020).

4. Skinner, G. \& Clemence, M. It's a fact, scientists are the most trusted people in world. Ipsos (18 September 2019); https://www. ipsos.com/en/its-fact-scientists-are-most-trusted-people-world

5. Somerville, R. C. \& Hassol, S. J. Phys. Today 64, 48-53 (October, 2011)

6. Corner, A., Shaw, C., Clarke, J. \& Wang, S. Communicating Environmental and Sustainability Science: Challenges, Opportunities, and the Changing Political Context (Climate Outreach, 2018); https://climateoutreach.org/content/uploads/ dlm_uploads/2018/07/Climate-Outreach-CommunicatingEnvironmental-and-Sustainability-Science-2.pdf

7. Flusberg, S. J., Matlock, T. \& Thibodeau, P. H. Environ. Commun. 11, 769-783 (2017).

8. Nerlich, B., Koteyko, N. \& Brown, B. Wiley Interdiscip. Rev. Clim. Change 1, 97-110 (2010).

9. Howarth, C. \& Anderson, A. Environ. Commun. 13, 713-722 (2019).

10. Nash, N. et al. Clim. Change 163, 63-82 (2019).

11. Moser, S. C. in Oxford Research Encyclopaedia, Climate Science (ed. Nisbet, M.) https://doi.org/10.1093/acrefore/ 9780190228620.013.436 (Oxford Univ. Press, 2017).

12. Anjos, S., Russo, P. \& Carvalho, A. J. Sci. Commun. https://doi. org/10.22323/2.20030211 (2021)

13. Torok, S., Pearce, K. \& Hassol, S. J. in Research Handbook on Communicating Climate Change (eds Holmes, D. \& Richardson, L.) 33-45 (Elgar, 2020).

14. Anderson, A. Media, Environment and the Network Society (Palgrave, 2014).

15. Corner, A., Markowitz, E. \& Pidgeon, N. F. Wiley Interdiscip. Rev. Clim. Change 5, 411-422 (2014).

16. Whitmarsh, L. \& Corner, A. Glob. Environ. Change 42, 122-135 (2017).

17. Howarth, C., Parsons, L. \& Threw, H. One Earth 2, 320-324 (2020).

18. Moser, S. C. \& Dilling, L. in Oxford Handbook of Climate Change and Society (eds Norgaard, R. et al.) 161-176 (Oxford Univ. Press, 2011).

19. Entradas, M. \& Bauer, M. W. Nat. Astron. 3, 183-187 (2019).

20. White, J. M. et al. Bull. Am. Astron. Soc. 53, 547-10 (2021).

Competing interests

The authors declare no competing interests. 